\title{
A Critical Review of EFL Writing Syllabus at Tertiary Level in the Arab World
}

\author{
El-Sadig Ezza (Corresponding Author) \\ Majma'ah University, Saudi Arabia \\ E-mail: elsadigezza@gmail.com \\ Khaled Al-Mudibry \\ Majma'ah University, Saudi Arabia \\ E-mail: k.almudibry@mu.edu.sa
}

Received: 26-05-2014

doi:10.7575/aiac.ijalel.v.3n.6p.80
Accepted: 01-07-2014

Published: 01-11-2014

URL: http://dx.doi.org/10.7575/aiac.ijalel.v.3n.6p.80

\begin{abstract}
Research into the written performance of Arab EFL learners centres for the most part upon their failure to handle a variety of assignments as prescribed by the writing syllabus. All things considered, writing problems are primarily attributed to the students' linguistic incompetence, immature mastery of rhetorical structure of the English text and Arabic discourse transfer (Al-Khuweileh and Al-Shoumali, 2000; Al-Hazmi and Schofield, 2007) By contrast, educational policies and teaching usually evade criticism. This study is an attempt to provide a new interpretation of learners' writing problems. In other words, it posits that writing problems could also be caused by the employment of outdated approaches and resources. To verify this argument, the present paper explored the existing writing courses in three Arab Universities, revealing that English Departments adopted approaches and materials characteristic of the 1940s and 1950s. Needless to say, unless new developments into the linguistic theory and writing pedagogy, i.e. genre analysis, contrastive rhetoric and discourse analysis, are incorporated into the existing writing syllabus, Arab EFL learners will continue to have writing problems.
\end{abstract}

Keywords: writing theories, writing pedagogy, writing materials, writing syllabus, process approach, product approach

1. Introduction

Research into the writing of Arab EFL learners focuses for the most part on their failure to handle a variety of assignments prescribed by the syllabus that has constituted their writing training. Generally speaking, writing problems are primarily attributed to the students' linguistic incompetence, immature mastery of rhetorical structure of the English text, Arabic discourse transfer and the like (Al-Khuweileh and Al-Shoumali, 2000; Al-Hazmi and Schofield, 2007; Fitze and Glasgow, 2009). Implicit in such research findings is the suggestion that learners are to blame for their failure to write satisfactorily. Apparently, educational policies have seldom been rendered responsible for defects in learning output in general and demonstration of writing skills in particular. In other words, such factors as teacher/student ratio, the number of students in the classroom, the number of writing courses, course materials and teaching methodology have rarely been addressed as possible causes of Arab EFL learners' writing problems. This paper posits that the institutional adoption of outdated writing approaches, and, therefore, the use of writing resources emanating from them are the main factors to complicate Arab EFL learners' writing practice. To show that this is so, the present paper will explore the existing writing syllabus in three Arab Universities: King Saud University (Saudi Arabia), Jordan University of Science and Technology (Jordan) and Al-Akhawayan University (Morocco) so as to answer two questions:

i. What are the writing approaches underlying the existing writing syllabus in the aforementioned universities?

ii. Do these approaches properly address the students' writing problems?

\section{Theoretical Background}

It is plausible to argue that part of the historical dilemma of writing pedagogy lies with the way it was approached vis-àvis the other language skills as can be shown by the formal and functional definitions of writing. Formally, writing is conceived as the "recording of human communication, using signs or symbols to represent the spoken words" (McMillan Encyclopedia, 1986:1317). On the other hand, writing is defined functionally as a "curiously solitary form of communication, addressed to an absent and often unknown reader" (Peters, 1986:169). Both definitions put writing at disadvantage since it is either seen as a secondary activity to reinforce speech or rendered somehow dissocialized form of communication. Indeed, during the audio-lingual era, the teaching of writing, technically known as controlled composition, was conceived to function as a service activity to reinforce listening and speaking skills (Freedman et al, 1983; Silva, 1990; Rivers, 1981).

However, there are three arguments supporting the fact that the fate of writing is not always bound up with the fate of the other skills. First, people do not always use writing to reinforce activities pertaining to the other skills being learned. In fact, there are a number of activities that can only be handled through the medium of writing. Viz. such 
activities as personal and official letters, books, newspapers, journals, etc. could not be conceived as just a reflection of other skills in any direct sense. Nor can it be possible to argue that these skills are as capable as writing in handling these same communicative functions. Second, there are a variety of writing problems that cannot be overcome by learners' competence in the other skills. This could have otherwise been the case if writing had indeed been approached simply as "homemaid" of the other skills. The writing literature shows that it is mostly through writing instruction, writing practice and teacher's feedback that students' writing can be improved (Krashen, 1984). Third, writing autonomy can be shown by its role as a differentiating factor between literate and illiterate members of the relevant speech community.

Regardless of the changing roles that writing has been assumed to play (Raimes, 1987), a number of approaches have to date been proposed to provide guidelines for (successful) writing pedagogy. The relevant literature abounds in three such approaches that have been most influential. These are the product approach, the process approach and the functional approach. As to the process approach, it is concerned with the finished text. Particularly, it is concerned with manipulation of lexical and grammatical structures in the written text. All writing forms characteristic of the oral and audio-lingual methods (technically known as controlled composition) are subsumed under this approach since they were concerned with the correct use of language structures. Of course, these forms of writing could not be expected to develop learners' composing abilities beyond the sentence level. What they did was either reinforce "paradigms, grammatical exercises, dictation, translation from native to target language" (Rivers, 1981:293) or functioned as a reinforcement for oral habits (Silva, 1990:11). The 1960s witnessed a new development into the product approach that came to be known in the literature as the "current-traditional rhetoric". This writing theory differs from its predecessor (i.e. controlled composition) in advocating writing at discourse level. It particularly emphasized the paragraph and its components (ibid, p. 14). According to Connor (1996: 59), current-traditional rhetoric benefited writing in three ways. First, "written products became a respectable object of academic enquiry". Second, writing was no longer taught by part-time instructors or Teaching Assistants. Third, a number of journals were devoted to research in writing. All in all, current traditional rhetoric contributed to free writing from being a mere reinforcement of its sister skills; viz. it became an independent skill and was practiced for its own sake.

However, the product approach became a subject for criticism in 1980s. For example, Freedman et al (1983:181) conceive of it as "pedagogically weak" for the insufficient attention it paid to the writing stages. On the other hand, Zamel (1983:165) argues that the product approach was "prescriptive, formulaic, and overtly concerned with correctness". A most comprehensive criticism of the product approach comes from Krashen (1984:25), who maintains that if the student-writer is "able to master all the rules of punctuation, spelling, grammar, and style that linguists have discovered and described", then their reward would be a Ph.D in Linguistics but they would never be competent writers. Therefore, owing to what was considered drawbacks in the product approach, the late 1970s witnessed a shift to the process approach that focuses on writing as an "explanatory and generative process whereby writers discover and reformulate their ideas as they attempt to approximate meaning" (Zamel, 1983:165). According to Raimes (1983:216), from the process approach perspective, "composing means expressing ideas, conveying meaning; composing means thinking". Obviously, then, the manipulation of linguistics structures would be considered the most peripheral aspect of writing. It is argued further in this connection that by preoccupying themselves with the formal aspects of writing, the students would do no more than "lock themselves into a semantic and rhetorical prison" (ibid). Instead, the prime concern for classroom activities would, therefore, be generating preliminary ideas, doing prewriting activities, outlining, getting started, producing first drafts, editing, revising, etc. (Jordan, 1997:167).

As it was the case with its predecessor, the process approach came under severe attack by the functionalists. Other things being equal, it was argued to "overemphasize the individual psychological functioning and neglect the sociocultural context" of writing. Therefore, the argument goes, it "operates in a socio-cultural vacuum" (Horowitz, 1986, p. 144). Due to these considerations, the late 1970 s witnessed a shift to a new direction in writing pedagogy where more attention was paid to the social (and cultural) context of writing as demonstrated in the literature produced by the advocates of the communicative, the functional and the genre theories, to mention but some. For instance, the functional approach to writing was developed as the result of linguists' dissatisfaction with the structural and transformational models that dominated language study and education during the first half of the $20^{\text {th }}$ century. It was widely acknowledged to introduce dramatic changes that have continued to shape language study and education. It persuaded language educators that the structural and transformational view of language does not adequately account for language as a system of communication; writing researchers particularly started to approach the written text as a "communicative event rather than something that illustrates a theoretical point" (Couture, 1986, p. 2).

\section{Review of Previous Research}

Generally speaking, research into Arab EFL learners' writing falls into two categories as illustrated by the studies that have been selected for review: cross-cultural studies and instruction-based studies. As to the first category, there are three studies that attempted to approach learners' writing cross-culturally. First, Al-Jamhoor (2001) applied a crosscultural analysis to the writing of Arab-speaking Learners of English. He particularly researched writing problems that were perceived to face Arab EFL learners at Imam University, Saudi Arabia. Fifty students were asked to write essays in English and Arabic. These essays were, then, compared to essays written by a control group, consisting of fifty American students at Michigan State University. The researcher concluded that the Arabic speaking students used fewer conclusions, $t$-units but more discourse units than their American counterparts. Since the research did not start from a clear-cut pedagogical objective, it is uncertain if these findings can be employed to support a call for specific educational procedures to improve learners' composing competence. Second, Al-Khuweileh and Al Shoumali (2000) set out to investigate the association between poor writing in English and Arabic. Data was collected from the writing 
of 150 students at Jordan University of Science and Technology. The results confirmed the generally held belief that poor writing in the mother tongue usually correlates with poor writing in the target language. Third, Daoud (1998) studied the role of exchange strategies in improving Arab EFL learners' writing skills and in changing their attitudes towards the target language culture. The subjects of the study were Syrian ESP medical students at Damascus University. They were required to exchange essays with American counterparts. The subjects were particularly asked to write about "their personalities, lives, and culture etc." where such aspects of writing as "topic sentence, and support were emphasized" (p.391). The experiment was implemented within a framework of an ESP course that centres upon the teaching of the four skills. The results showed that the subjects "lacked appropriate vocabulary and expressions"; also some of them were found to be "aggressive in addressing their American counterparts" but they were informed by the researcher that "good writers ... had to find their way to people hearts and minds by presenting convincing arguments supported by concrete details and examples" (p. 397).

The instruction-based category also comprises three studies: Al-Hazmi (2006), Al-Hazmi and Schofield (2007) and Fitze and Glasgow (2009). As to the first study, Al-Hazmi (2006) conducted a study against the background that EFL writing in the Arab world suffers from traditional teaching which renders it "abstracted, depersonalized and product oriented" (p. 35). These problems, the researcher contends, could only be overcome by applying the process approach to writing pedagogy since it is "uniquely suited to promoting the skills of critical thinking and self-reflection" (p.36). However, despite all this enthusiasm, all the researcher did was elicit research data using an open-ended questionnaire. There was no written assignment to support the researcher's faith in the strengths of the process approach; the subjects simply answered questions about what an ideal writer would do when drafting a text, knowing that "their language proficiency in absolute terms can only be termed as pre-intermediate" (p.39); viz. none is an ideal writer! The second study (Al-Hazmi and Schofield (2007)), investigated the effect of enforced revision and peer feedback on the students' writing quality. The study was intended to improve the writing of low-proficiency Saudi Students at tertiary level. A total of 51 third level students at King Khalid University participated in the experiment. At the pretest stage all the subjects wrote two drafts but only the experimental group was provided with a checklist to consider at the post-test stage. The researchers concluded that the subjects "were not ready to abandon the traditional surface error focus of their classroom" despite the researchers' effort to improve their English writing (p.237).

Third, Fitze and Glasgow (2009) conducted action research to investigate tense formation in Arab EFL writing. The subjects of the study were low-level students at Dubai Women's College, United Arab Emirates. The subjects were instructed in English Grammar and were later required to submit a written assignment. Results indicated that grammatical accuracy of students writing can be notably enhanced by providing teacher-led grammar instruction prior to independent writing. The problem with his study is that it follows from a bottom-up approach to writing where mastery of linguistic competence is conceived as a necessary condition for writing. This could have been the case during the traditional and structural writing practices in the first half of the $20^{\text {th }}$ century but sure enough could not receive theoretical support at post-discourse era.

\section{Existing Writing Syllabus in Some Arab Universities}

This section reviews the writing syllabus in three Arab Universities: King Saud University (Saudi Arabia), Jordan University of Science and Technology (Jordan) and Al-Akhawayan University (Morocco) as summarized in table (1) below consecutively. These institutions have been selected for three reasons. First, they come from different Arab regions. Second, they belong to the group of top Arab universities both nationally and regionally according to the Spanish ranking of the world universities (2013). Third, unlike many universities in the group, they have posted all the course components needed for this research online.

The research materials consist of three first year writing courses. The content of these courses will be examined in the light of the writing literature reported in (2) above so as to measure the claim made at (1) above that Arab EFL learners' writing problems are primarily caused by the use of outdated approaches.

Table 1. Components of writing courses

\begin{tabular}{|c|c|c|}
\hline King Saud University & $\begin{array}{l}\text { Jordan University of Science } \\
\text { and Technology }\end{array}$ & Akhawayan University \\
\hline $\begin{array}{l}\text { Eng. 111: Basic Language } \\
\text { Skills }\end{array}$ & ENG. 115: Writing (1) & $\begin{array}{l}\text { AWT10001: Academic Writing } \\
\text { (1) }\end{array}$ \\
\hline Modal auxiliaries & Pronouns & Dependent and independent \\
\hline Present and past perfect & The topic sentence & sentence \\
\hline Nouns & The basic sentence pattern & Basic sentence types \\
\hline Passive sentences & Coordination & Punctuation and capitalization \\
\hline Adjectival clauses & Description & Combining sentences and \\
\hline Noun clauses & Fragments & clauses \\
\hline Direct and indirect speech & Subordination & Pre-writing strategies \\
\hline Using 'if' & Modifiers & Writing a paragraph \\
\hline Sentence patterns & Parallelism & Types of paragraph \\
\hline Connecting idea & $\begin{array}{l}\text { Comparison and contrast } \\
\text { Correlative conjunctions } \\
\text { Punctuation }\end{array}$ & Self- and peer-editing \\
\hline
\end{tabular}


The table clearly indicates that the English Departments in these Universities approach writing from a product perspective. Even worse, they advocate the product version characteristic of the oral and audio-lingual methods since the primary concern of the writing courses is the sentence and its components. Such a view of writing pedagogy reduces writing to a mere exercise in the English grammar. It was shown in (2) above that linguists have since 1970s abandoned the structural and transformational concept of the sentence as the basic unit of language. Thus, the focus of linguistic enquiry has moved from the sentence to the text as the basic unit of linguistic communication. These developments have enormously revolutionized writing pedagogy in different parts of the world (cf. Couture, 1986; McDonough and Show, 1993) but it seems to have fallen on a deaf ear in the Arab world since writing course designers still belief in the acquisition of grammar as a key to the mastery of writing skills.

Grammar-based approach to writing, so to speak, can be argued to be defective in three respects. First, grammar is an open-ended phenomenon to the extent that it jeopardizes writing pedagogy. Viz. If the fate of writing is bound up with acquisition of grammar, learners could not be expected to study and practise writing properly and the eight terms of college teaching might not be enough to cover the particularities of grammar - knowing that the bulk of grammar is of no practical use for the students' writing needs, e.g. generating surface structures from deep structures has nothing to do with composing at paragraph and essay levels. Second, even when the argument that mastery of grammar determines success in writing is taken for granted, there still remains the question about the nature of grammar needed in the writing programme; for grammar comes in different schools (formal/functional), theories (structural/ transformational), types (theoretical/pedagogical), etc. which are for the most part mutually exclusive, and cannot, therefore, be compromised into a coherent writing programme. Third, emphasizing grammar in a writing course overshadows the nature of writing as a communication skill where grammar is one of many resources that writers resort to in order to enrich their communicative intent. In fact, grammar operates at a linguistic level below that of the basic unit of writing, i.e. the paragraph where emphasis will primarily be on textuality, i.e. the relationship between sentences, rather than grammaticality, i.e. the well-formedness of the sentence (Xu, 1991).

The writing components in the three columns in table above strongly justify both the research focus and findings reported in section (3) above. In other words, both types of research (cross-cultural and instruction-oriented) explicitly considered the linguistic difficulties experienced by the research subjects. It has been argued in this section that linguistic information is open-ended and cannot, therefore, be sufficiently handled even in pure grammar courses, let alone the amount incorporated into the writing courses selected for analysis in this study. Thus, since the role of grammar has been emphasized at the expense of the writing skills, e.g. topic sentence, paragraphing, cohesion, coherence, etc., the students will continue to have writing problems. As to the research findings, it is suffice to point out that Al-Hazmi and Schofield (2007:237) concluded that their research subjects "were not ready to abandon the traditional surface error focus of their classroom". It is unfortunate that the students were not properly trained in writing but are still blamed for a job that was never theirs. Sure enough, as long as writing instruction focuses on grammar, traditional writing practice will always shape their writing attempts.

\section{Conclusion}

As a practical activity, language teaching is assumed to draw on insights from many disciplines (Brumfit and Johnson, 1979). Linguistics has been a major discipline to fuel classroom activities. Where writing is concerned, it was once practised as "sentences in isolation" to use Widdowson's (1979) term, at times when the dominating schools of linguistics approached the sentence as the basic unit of language. The second half of the $20^{\text {th }}$ century witnessed new developments into the linguistic theory whereby the "text" came to be viewed as the basic unit of language. Once again writing pedagogy has been greatly influenced in that classroom activities have focused on the paragraph as a unit of writing. Examination of the writing syllabus of some Arab universities has shown that writing practice assumes a bottom-up approach, emphasizing the sentence and its constituents at the expense of the skills needed to write coherent paragraphs. Thus, since the sentence and the paragraph are two different levels of linguistic representation, the current writing syllabus cannot be expected to improve learners composing skills at textual level.

\section{References}

Al-Hazmi, S. (2006). Writing Reflection: Perceptions of Arab EFL Learners. South Asian Language Review, XVI (2): 36-52.

Al-Hazmi, S. And P. Schofield. (2007). Enforced Revision with Checklist and Peer Feedback in EFLWriting: The Example of Saudi University Students. Scientific Journal of King Faisal University (Humanities and Management Sciences), 8(2), 237-267.

Al-Khuweileh, A. A. and A. Al-Shoumali. (2000). Writing Errors: A study of the Writing Ability of Arab Learners of Academic English and Arabic at University [Abstract]Language, Culture and Curriculum, 13 (2): 174-183.

Al-Jamhoor, A. (2001). A Cross-Cultural Analysis of Written Discourse of Arabic- Speaking Learners of English. Journal of King Saud University (Language an Translation), 13(1): 25-44.

Allwright, R. (1979). Language Learning Through Communicative Practice. In C. I. Brumfit and K. Johnson

(Eds.), The Communicative Approach to Language Teaching, 167- 181. Oxford: Oxford University Press.

Connor, U. (1996). Contrastive Rhetoric: Cross Cultural Aspects of Second Language Writing. Cambridge: Cambridge University Press. 
Daoud, S. A. (1998). How to Motivate EFL Learning and Teaching of Academic Writing by Cross-Cultural Exchanges. English for Specific Purposes, 17 (4), 391-412.

Fitze, M. \& Glasgow, R. (2009). Input Enhancement and Tense Formation in Arab EF Writing. Retrieved from http://www.tesoljournal.com/Articles/Example_Article.doc

Freedman, A., I. Pringle, Y. Yalden (Eds.). (1983). Learning to Write: First Language/Second Language, 179- 189. New York: Longman.

Harsh, W. (1982). Linguistics and TESOL: A Turbulent Twenty Years. Forum, xx(v), 2-8.

Hymes, D. (1979). On Communicative Competence. In C. I. Brumfit and K. Johnson (Eds.), The Communicative Approach to Language Teaching, 5- 26. Oxford: Oxford University Press.

Jordan, R. R. (1997). English for Academic Purposes. Cambridge: Cambridge University Press.

Krashen, S. D. (1984). Writing Research: Theory and Applications. Oxford: Pergamon Press.

McDonough, J. \& Show, C. (1993). Materials and methods in ELT: A Teacher's Guide Oxford: Blackwell.

McMillan Encyclopedia. (1986). London: McMillan Limited.

Peters, P. (1986). Getting the Theme Across: A Study of Dominant Function in the Academic Writing of University Students. In B. Couture (Ed.): Functional Approaches to Writing: Research Perspectives, 169-185. London: Frances Printer.

Radford, A. (1986). Transformational Grammar. Cambridge: Cambridge University Press.

Raimes, A. (1987). Why Write? From Purpose to Pedagogy. Forum, xxv(4), 36-41.

Rivers, W. (1981). Teaching Foreign Language Skills. Chicago: University of Chicago Press.

Silva, T. (1990). Second Language Composition Instruction: Developments, Issues and Directions. In B. Kroll (Ed.): Second language writing: Research Insight for Classroom, 11-23. Cambridge: Cambridge University Press.

Van Dijk, T. A. (1972). Some Aspects of Text Grammars: A Study of Theoretical Linguistics and Phonetics. The Hague: Mouton.

Widdowson, H. (1979). Directions in the Teaching of Discourse. In C. J. Brumfit and K. Johnson (Eds.): The Communicative Approach to Language Teaching, 49-60. Oxford: Oxford University Press.

X, G. Q. 1991. The Major Concerns of Text Linguistics and Their Relevance to the Teaching of Writing [abstract]. ERIC Document No. 338060.

Zamel, V. (1983). The Composing Processes of Advanced ESL Students: Six Case Studies. TESOL Quarterly, 17(2): $165-186$.

\section{Appendix}

\section{Courses' links}

King Saud University

http://colleges.ksu.edu.sa/Arabic\%20Colleges/Arts/English/englishdepartment1/Pages/BAinarts.aspx

Jordan University of Science and Technology

http://www.just.edu.jo/FacultiesandDepartments/FacultyofScienceandArts/Departments/EnglishforAppliedStudies/Lists /Courses/StudentView.aspx

Al-Akhawayan University

http://www.aui.ma/VPAA/LanguageCentre/awt1001.htm 